Int. J. Electrochem. Sci., 15 (2020) 3980 - 3995

International Journal of

ELECTROCHEMICAL

SCIENCE

WWW.electrochemsci.org

\title{
Investigation of Commercial Tungsten Carbide as an HER Electrocatalyst in PEMWE
}

\author{
Xiaofeng Xie, Lanshan Liu, Shusheng Chen, Yuanquan Zhou, Xiaohong $\mathrm{Hu}^{*}$ \\ Hubei Key Lab of Electrochemical Power Source, College of Chemistry and Molecular Sciences, \\ Wuhan University. Wuhan Hubei, 430072, China \\ *E-mail: xhhu88@whu.edu.cn
}

doi: $10.20964 / 2020.05 .05$

Received: 8 December 2019 / Accepted: 21 February 2020 / Published: 10 April 2020

Proton electrolyte membrane water electrolysis (PEMWE) is a promising hydrogen generation method limited by the high cost, such as those costs associated with noble electrocatalysts. Herein, we investigate commercial tungsten carbide (WC), a potential substitute for Pt, as a hydrogen evolution reaction (HER) electrocatalyst in PEMWE. We adopted two sizes of $\mathrm{WC}, 400 \mathrm{~nm}$ and $1 \mu \mathrm{m}$, optimized the electrode fabrication method and running conditions. The results show that the smaller WC does not provide stable performance and operating at high current density and low temperature is more competitive with Ptbased electrolysis. In addition, the most serious drawback is the increased cell voltage on restart after long-term power-off due to considerable WC oxidation, which leads to a decrease in the catalytic carbide carbon. Luckily, this can be offset by effective $\mathrm{O}_{2}$ isolation in the cathode, such as $\mathrm{H}_{2} \mathrm{O}$ sealing or pumping with $\mathrm{H}_{2}$. WC is an economic alternative as a HER electrocatalyst in PEMWE with optimized conditions and an $\mathrm{O}_{2}$ isolation strategy during an interrupted operation. We provide a practical method to reduce the cost of the HER electrocatalyst.

Keywords: Proton electrolyte membrane water electrolysis; Tungsten carbide; Hydrogen evolution reaction; Protection strategy.

\section{$\underline{\text { FULL TEXT }}$}

(C) 2020 The Authors. Published by ESG (www.electrochemsci.org). This article is an open access article distributed under the terms and conditions of the Creative Commons Attribution license (http://creativecommons.org/licenses/by/4.0/). 